\title{
The Relationship between Dietary Vitamin A Intake and the Levels of Sialic Acid in the Breast Milk of Lactating Women
}

\author{
Yang QIAO ${ }^{1,2}$, Jinlu FeNG ${ }^{3}$, Jianping YANG ${ }^{2}$ and Guixiong GU ${ }^{1, *}$ \\ ${ }^{1}$ Department of Child Health, Affiliated Children's Hospital of Soochow University, Suzhou 213001, China \\ ${ }^{2}$ Department of Child Health, Shanxi Maternal and Child Health Hospital, Taiyuan 030013, China \\ ${ }^{3}$ Department of Anesthesia, Shanxi Tumor Hospital, Taiyuan 030013, China
}

(Received November 14, 2012)

\begin{abstract}
Summary Sialic acid (SA) is an important nutrient but few studies have examined the link between dietary intake and breast milk sialic acid. The purpose of this observational study was to assess the potential relationship between human breast milk sialic acid levels and dietary nutrition intake $40 \mathrm{~d}$ postpartum. The study population included 90 healthy women who were lactating. Human breast milk SA concentrations were measured using fluorescence detector-high performance liquid chromatography (HPLC-FLD) analysis and nutritional intake was estimated by a computerized validated food frequency questionnaire. SA in human breast milk was bound to free oligosaccharides $(82.35 \%)$, protein $(15.27 \%)$ and free sialic acid $(2.37 \%)$. The findings of this study indicate that subjects with higher milk SA levels showed statistically higher levels of vitamin A compared with subjects with lower SA levels $(423.48 \pm 172.29$ vs $602.22 \pm 126.46 \mu \mathrm{g} / \mathrm{d}, p=0.000)$. In addition, there was a certain association (standardized coefficients $=0.713 ; p=0.000$ ) between breast milk SA and vitamin A intake in healthy young subjects. This study demonstrated that dietary vitamin A intake has a certain relationship with breast milk SA concentrations. This may be attributed to the influence of vitamin A on sialic acid glycoprotein and sialic acid mucopolysaccharide in the human body or the common food sources for vitamin A and sialic acid. Additional study is required to further investigate this relationship.
\end{abstract}

Key Words sialic acid, breast milk, vitamin A, diet, nutrition

Sialic acid (SA) is an integral part of the ganglioside structure in synaptogenesis and neural transmission in humans $(1,2)$ and because it can improve learning and memory (3), it is regarded as an important nutrient in early life (4). For infants, breast milk is the only rich source of sialic acid (5-7). Thus, the SA levels of breast milk are vitally important. Although maternal dietary intake of nutrients such as fatty acid and choline affects breast milk nutrition during lactation, there have been no studies examining the effects of sialic acid on lactation nutrition $(8,9)$. The purpose of this observational study was to assess the potential relationship between breast milk SA levels and dietary nutrition intake $40 \mathrm{~d}$ postpartum.

\section{Methods and Materials}

Subjects. The study population included 90 healthy women who were lactating. None of the study participants were reported to have inflammatory-related diseases, tumor diseases or cardiovascular diseases.

\footnotetext{
*To whom correspondence should be addressed.

E-mail: szggx000@163.com

Abbreviations: HPLC-FLD, fluorescence detector-high performance liquid chromatography; SA, sialic acid; TCA, trichloroacetic acid.
}

None of the participants were taking vitamin or trace elements supplements. Each participant signed a written informed consent of acceptance that was previously approved by the Regional Ethical Review Board at Maternity and Child Care Hospital of Shanxi. This research was conducted in accordance with the Helsinki Declaration (2003) of the World Medical Association (SXFY2010017).

Preparation of human milk. Milk samples were drawn on day 40 of lactation from breast-feeding mothers of term infants (infants born at a gestational age between 37 and 42 completed weeks) when lactation ended each time. The milk sample $(10 \mathrm{~mL})$ was collected within $15 \mathrm{~min}$ and was stored at $-25^{\circ} \mathrm{C}$. Sialic acid concentrations in breast milk were determined by fluorescence detector-high performance liquid chromatography (HPLC-FLD). All the experimental instruments and main chemicals were purchased from Waters (Milford, MA) and Sigma-Aldrich (St. Louis, MO), respectively.

Sialic acid assay.

Determination of free sialic acid: The following procedure was used to determine free sialic acid concentrations (10). Breast milk (500 $\mu \mathrm{L}$ ) and an equal volume of $10 \%$ trichloroacetic acid (TCA) were placed into a centrifugal pipe, mixed using a vortex, iced for $10 \mathrm{~min}$ and centrifuged at $3,000 \mathrm{r} / \mathrm{min}$ at $4^{\circ} \mathrm{C}$ for $30 \mathrm{~min}$. The 
supernatant was removed and the remaining pellet was washed with cold 5\% TCA $(500 \mu \mathrm{L})$. The pellet and TCA were then centrifuged at $3,000 \mathrm{r} / \mathrm{min}$ at $4^{\circ} \mathrm{C}$ for $30 \mathrm{~min}$. The combined supernatant from both washes (approximately $500 \mu \mathrm{L}$ ) was filtered using a $0.22 \mu \mathrm{m}$ filter membrane. The filtered supernatant $(90 \mu \mathrm{L})$ was combined with 1,2-diamino-4,5-methylenedioxybenzene (DMB; $10 \mu \mathrm{L}$ ) and set aside in the dark for $150 \mathrm{~min}$. Chromatographic analysis proceeded after the solution cooled.

Determination of oligosaccharides-bound sialic acid: The total amount of oligosaccharides-bound sialic acid and free sialic acid was determined using the following method (10). The remaining supernatant (approximately $410 \mu \mathrm{L}$ ) from the combined washes used to determine the amount of free sialic acid was combined with an equal volume of $0.1 \mathrm{mmol}$ trifluoracetic acid/L and hydrolyzed for $30 \mathrm{~min}$ at $80^{\circ} \mathrm{C}$. The supernatant was then filtrated using a $0.22 \mu \mathrm{m}$ filter membrane. DMB $(10 \mu \mathrm{L})$ was added to the supernatant $(90 \mu \mathrm{L})$ and the solution placed in the dark for $150 \mathrm{~min}$. Chromatographic analysis proceeded after the solution cooled.

Determination of protein-bound sialic acid: The precipitate from the initial wash to determine free sialic acid concentrations was combined with sulfuric acid (0.05 mol/L; $2 \mathrm{~mL}$ ) and hydrolyzed for $120 \mathrm{~min}$ at $80^{\circ} \mathrm{C}$ (10). Again, the supernatant was then filtrated using a $0.22 \mu \mathrm{m}$ filter membrane. DMB $(10 \mu \mathrm{L})$ was added to filtered supernatant $(90 \mu \mathrm{L})$, and placed in the dark for $150 \mathrm{~min}$. Chromatographic analysis proceeded after the solution cooled.

Dietary intake assessment. The dietary intake of the study participants was assessed by a 72-h dietary recall questionnaire. Nutrient intake was computed using a dietary evaluation validated for Chinese people (11). All foods and beverages consumed throughout the 72-h study period were recorded (12). Quantities were weighed when possible and information about foods, including brand names, food preparation methods and all ingredients used in food preparation methods were recorded when possible. Food models, measurement aids and food-specific units were used to estimate amounts consumed. Each individual's intake of energy, fat, fiber, protein, vitamins and minerals was determined from their 72-h dietary recall.

Statistical analysis. Results are presented as arithmetic means and standard deviations. The KolmogorovSmirnov test was used to determine variable distribution. Study participants were divided into two groups, lower and higher SA levels, based on the median level of breast milk SA on postpartum day $40( \pm 7 \mathrm{~d})$. $t$-tests were used to test the differences in nutritional intake between the two groups. Chi-square tests were used to test the differences of frequency distributions in milk, beef, egg, mutton, and pork intakes between the igher vitamin A group and lower vitamin A group. Multiple linear regression analysis was used to analyze the relation of nutritional intake and breast milk SA on postpartum day $40( \pm 7 \mathrm{~d})$. All analyses were performed by SPSS for Windows 17.0 (SPSS Inc, Chicago, IL, USA). A $p$ value of less than 0.05 was considered significant.
Table 1. Sialic acid concentrations in human milk $40 \pm 7$ d postpartum $(\mathrm{mg} / \mathrm{L}$, mean $\pm \mathrm{SE})$.

\begin{tabular}{lcc}
\hline Distribution of sialic acid & $\begin{array}{c}40 \mathrm{~d} \text { after birth } \\
(n=90)\end{array}$ & $\begin{array}{c}\text { Percent } \\
(\%)\end{array}$ \\
\hline Free & $16.96 \pm 4.38$ & 2.37 \\
Oligosaccharide-bound & $588.19 \pm 56.66$ & 82.35 \\
Protein-bound & $109.10 \pm 23.63$ & 15.27 \\
Total sialic acid & $714.25 \pm 64.39$ & 100 \\
\hline
\end{tabular}

Table 2. Total nutrient intakes of the subjects categorized according to the median $(719 \mathrm{mg} / \mathrm{dL})$ of breast milk SA concentration.

\begin{tabular}{lcc}
\hline & $\begin{array}{c}\text { Lower milk SA } \\
(n=45)\end{array}$ & $\begin{array}{c}\text { Higher milk SA } \\
(n=44)\end{array}$ \\
\hline Protein $(\mathrm{g} / \mathrm{d})$ & $70.71 \pm 25.03$ & $77.09 \pm 25.94$ \\
Carbohydrate $(\mathrm{g} / \mathrm{d})$ & $199.47 \pm 65.25$ & $224.93 \pm 82.41$ \\
Vitamin A $(\mu \mathrm{g} / \mathrm{d})$ & $423.48 \pm 172.29$ & $602.22 \pm 126.46^{* *}$ \\
Vitamin E $(\mathrm{mg} / \mathrm{d})$ & $19.84 \pm 12.63$ & $23.82 \pm 17.81$ \\
Vitamin C $(\mathrm{mg} / \mathrm{d})$ & $56.96 \pm 10.23$ & $60.98 \pm 13.31$ \\
Zinc $(\mathrm{mg} / \mathrm{d})$ & $9.44 \pm 3.52$ & $10.42 \pm 3.25$ \\
Calcium $(\mathrm{mg} / \mathrm{d})$ & $490.16 \pm 184.20$ & $563.18 \pm 243.29$ \\
Manganese $(\mathrm{mg} / \mathrm{d})$ & $4.64 \pm 1.60$ & $5.28 \pm 1.38$ \\
Iron $(\mathrm{mg} / \mathrm{d})$ & $17.87 \pm 5.91$ & $17.12 \pm 6.23$ \\
Selenium $(\mu \mathrm{g} / \mathrm{d})$ & $36.66 \pm 14.57$ & $36.26 \pm 14.45$ \\
Polyunsaturated fatty & $11.31 \pm 7.14$ & $13.98 \pm 8.79$ \\
$\quad$ & & \\
\hline
\end{tabular}

** $p \leq 0.01$.

\section{Results}

Distribution of breast milk SA

There were three major forms in human breast milk SA. Most of the sialic acid in human breast milk was bound to free oligosaccharides $(82.35 \%)$ and $15.27 \%$ of sialic acid in human breast milk was bound to protein. Little of the sialic acid in human breast milk was free sialic acid (2.37\%) (Table 1).

Nutrient intakes and breast milk $S A$

There were no statistically significant differences in macronutrient (carbohydrate, protein, vitamin E, zinc, selenium, iron or polyunsaturated fatty acid) intake between subjects with higher and lower milk SA (Table 2 ). Subjects with higher breast milk SA presented significantly higher vitamin A intake $(p<0.01)$ when compared with individuals with lower milk SA (Table 2).

There was a certain association between breast milk SA and vitamin A intake in healthy young subjects (standardized coefficients $=0.713, p=0.000$ ) after adjustment for maternal general characteristics (including education and age) as shown in Table 3.

The frequency distributions of Vitamin A intake

Study participants were divided into two groups, lower and higher vitamin A intake, based on the median level of vitamin A intake on postpartum day 40 ( $\pm 7 \mathrm{~d})$. Subjects with higher vitamin A intake were 47 cases 
Table 3. Multiple linear regression analysis of human milk SA $40 \pm 7$ d postpartum $(\alpha=0.01)$.

\begin{tabular}{lccrrr}
\hline Independent variables & Unstandardized B & Unstandardized B & $t$ & $p$ & $\begin{array}{c}\text { Standardized } \\
\text { coefficients beta }\end{array}$ \\
\hline Protein $(\mathrm{g} / \mathrm{d})$ & 0.069 & 0.288 & 0.024 & 0.811 & 0.027 \\
Carbohydrate $(\mathrm{g} / \mathrm{d})$ & -0.038 & 0.081 & -0.472 & 0.638 & -0.044 \\
Vitamin A $(\mu \mathrm{g} / \mathrm{d})$ & 0.264 & 0.035 & 7.432 & 0.000 & 0.713 \\
Vitamin E $(\mathrm{mg} / \mathrm{d})$ & -1.006 & 0.459 & -2.189 & 0.032 & -0.241 \\
Vitamin C $(\mathrm{mg} / \mathrm{d})$ & -0.143 & 0.478 & -0.299 & 0.766 & -0.027 \\
Zinc $(\mathrm{mg} / \mathrm{d})$ & -0.415 & 1.987 & -0.209 & 0.835 & -0.022 \\
Calcium $(\mathrm{mg} / \mathrm{d})$ & 0.009 & 0.028 & 0.311 & 0.756 & 0.029 \\
Manganese $(\mathrm{mg} / \mathrm{d})$ & -1.659 & 4.594 & -0.361 & 0.719 & -0.039 \\
Iron $(\mathrm{mg} / \mathrm{d})$ & -1.735 & 1.071 & -1.621 & 0.109 & -0.163 \\
Selenium $(\mu \mathrm{g} / \mathrm{d})$ & 0.591 & 0.437 & 1.353 & 0.180 & 0.132 \\
\hline
\end{tabular}

Table 4. The frequency distributions of vitamin A intake.

\begin{tabular}{|c|c|c|c|c|c|c|c|c|c|}
\hline Group & Milk & Beef & Pumpkin & Egg & Seafish & Pork & Carrot & Mutton & Corn \\
\hline Higher group & $47(64.4)$ & $30(83.3)$ & $21(70.0)$ & $47(56.0)$ & $24(82.8)$ & $43(81.1)$ & $30(73.2)$ & $30(78.9)$ & $28(87.5)$ \\
\hline Lower group & $26(35.6)$ & $6(16.7)$ & $9(30.0)$ & $37(44.0)$ & $5(17.2)$ & $10(18.9)$ & $11(26.8)$ & $8(21.1)$ & $4(12.5)$ \\
\hline
\end{tabular}

$\chi^{2}=23.85, p=0.002 . p<0.05$ was considered significant.

Table 5. Vitamin A intake of the subjects categorized according to the median $(17 \mathrm{mg} / \mathrm{dL})$ of breast milk free SA concentration.

\begin{tabular}{lcc}
\hline & $\begin{array}{c}\text { Lower SA } \\
(n=48)\end{array}$ & $\begin{array}{c}\text { Higher SA } \\
(n=42)\end{array}$ \\
\hline Vitamin A $(\mu \mathrm{g} / \mathrm{d})$ & $490.42 \pm 171.99$ & $536.11 \pm 175.83$ \\
$t$ & 1.244 & \\
$p$ & 0.217 & \\
\hline
\end{tabular}

Table 6. Vitamin A intake of the subjects categorized according to the median $(598 \mathrm{mg} / \mathrm{dL})$ of breast milk SA concentration bound to oligosaccharides.

\begin{tabular}{lcc}
\hline & $\begin{array}{c}\text { Lower SA } \\
(n=45)\end{array}$ & $\begin{array}{c}\text { Higher SA } \\
(n=45)\end{array}$ \\
\hline Vitamin A $(\mu \mathrm{g} / \mathrm{d})$ & $426.78 \pm 173.29$ & $596.70 \pm 129.14$ \\
$t$ & 5.274 & \\
$p$ & 0.000 & \\
\hline
\end{tabular}

and lower vitamin A intake were 43 cases. The frequency distributions of vitamin A intake in the two groups are presented in Table 4 . The frequency distributions of milk, beef, egg, mutton, and pork intakes in the higher vitamin A group were significantly higher when compared with individuals with lower vitamin A intake $\left(\chi^{2}=23.85, p=0.002\right)$.
Table 7. Vitamin A intake of the subjects categorized according to the median $(103 \mathrm{mg} / \mathrm{dL})$ of breast milk SA concentration bound to protein.

\begin{tabular}{lcc}
\hline & $\begin{array}{c}\text { Lower SA } \\
(n=44)\end{array}$ & $\begin{array}{c}\text { Higher SA } \\
(n=46)\end{array}$ \\
\hline Vitamin A $(\mu \mathrm{g} / \mathrm{d})$ & $442.44 \pm 130.30$ & $578.03 \pm 186.26$ \\
$t$ & 3.99 & \\
$p$ & 0.000 & \\
\hline
\end{tabular}

Vitamin A intake of the subjects categorized according to the median of breast milk free SA concentration

Study participants were divided into two groups, lower and higher breast milk free SA concentration based on the median level of free SA concentration on postpartum day 40 ( \pm 7 d). Subjects with a higher breast free SA concentration presented significantly higher vitamin A intake $(t=1.244, p<0.01)$ when compared with individuals with a lower free SA concentration, SA concentration bound to oligosaccharides and SA concentration bound to protein (Table 5).

Vitamin A intake of the subjects categorized according to the median of breast milk SA concentration bound to oligosaccharides

Study participants were divided into two groups, lower and higher breast milk SA concentration bound to oligosaccharides based on the median level of SA concentration bound to oligosaccharides on postpartum day 40 ( \pm 7 d). Subjects with higher breast SA bound to oligosaccharides presented significantly higher vitamin A intake $(t=5.274, p<0.01)$ when compared with indi- 
viduals with lower breast SA bound to oligosaccharides (Table 6).

Vitamin A intake of the subjects categorized according to the median of breast milk SA concentration bound to protein

Study participants were divided into two groups, lower and higher breast milk SA concentration bound to protein based on the median level of SA concentration bound to protein on postpartum day 40 ( \pm 7 d). Subjects with a higher breast SA concentration bound to protein presented significantly higher vitamin A intake $(t=3.99$, $p<0.01$ ) when compared with individuals with a lower breast SA concentration bound to protein (Table 7).

\section{Discussion}

The distribution of breast milk sialic acid during lactation was reported previously by Wang et al. (7). Carlson reported that the sialic acid concentration in human milk oligosaccharides was higher than sialic acid in human milk glycoproteins (13). Our results reveal that most sialic acid in human breast milk was bound to free oligosaccharides, whereas little was free sialic acid or bound to protein. The main reason is that as there are higher levels of oligosaccharides in breast milk than in bovine milk $(14,15)$, it would lead to the higher SA concentration in human milk oligosaccharides.

Although many essential nutrients are secreted into breast milk, including the fatty acid, docosahexaenoic acid (DHA) $(16,17)$, there have been few reports describing the relationship between maternal diet and sialic acid in breast milk. In this study it was observed that vitamin A intake during maternal lactation at $40 \mathrm{~d}$ had a high correlation with sialic acid concentration in breast milk. Wolf et al. $(18,19)$ indicated that vitamin A exerted its influence on mucopolysaccharide synthesis. Wolf et al. (20-22) also pinpointed the defect in glycoprotein synthesis caused by vitamin A deficiency at the protein-glycosylation step. Whereas sialic acid exists only as free mucosaccharides in very low concentrations in the body fluids of humans and animals, it usually occurs in glycosidic linkages of mucopolysaccharide, glycoproteins, gangliosides and lipopolysaccharides $(23,24)$. Although from questionnaire survey there was poor evidence, we suppose vitamin A impacted the occurrence of sialic acid by influencing the synthesis of glycoproteins and mucopolysaccharide by affecting the binding of sialic acid. We hope it will serve as a basis for future clinical research and has an important meaning for the research of human milk SA. Additional study is required to further investigate this relationship. Another explanation for the relationship between vitamin A intake and human breast milk sialic acid $40 \mathrm{~d}$ postpartum may lie in the native food sources of vitamin A and sialic acid. In the current study we found the volunteers whose milk SA was higher could have greater food sources of vitamin A. The best sources for vitamin A are liver (3,000-15,000 $\mu \mathrm{g}$ retinol/100 g) and fish liver oils. Significant levels of vitamin A are also present in milk, whole eggs and egg products (25). Our data displayed the higher vitamin A intake group consumed more milk, eggs, beef, pork, and mutton. Tangvoranun- takul et al. reported that sialic acid was present in red meats, milk and eggs (26) and Varki (27) also indicated that red meat and milk were sialic acid dietary sources. Wang reviewed sialic acid levels in beef, lamb, pork and chicken (4). Although high levels of sialic acid are usually found in animal sources, sialic acid can also be found in plant foods. Cooked corn, surprisingly, not only contained relatively high sialic levels (4), but also contained high levels of beta carotene, which is an effective source of vitamin A $(28,29)$. Interestingly, our data also showed higher corn intake was consistent with higher vitamin A intake. This research indicates that there is some commonality in foods that are rich in sialic acid and vitamin A. Based on our clinical data, we can assume when mothers who were lactating consumed food enriched with vitamin A such as red meat, eggs, milk, and corn, they were also consuming foods which contained relatively high levels of sialic acid. This would have resulted in high levels of sialic acid secreted into breast milk.

In conclusion, this study demonstrated that dietary vitamin A intake has a certain relationship with maternal milk SA concentrations. This relationship may be attributed to the influence of vitamin $\mathrm{A}$ on the sialic acid glycoprotein and sialic acid mucopolysaccharide or the common food sources for vitamin A and sialic acid. Additional study is required to further investigate this relationship.

\section{Acknowledgments}

We would like to thank the mothers and all volunteers who participated in this study. We would also like to mention the efforts of physician Yanjun Geng in providing assistance in the nutritional analysis and Professor Hongmei Yu for data analysis. We would like to extend our thanks to Miss Dandan Bai, who provided assistance and support along with the team of dedicated research nurses and ancillary staff.

This project was supported by the scientific research innovation projects of college graduate students in Jiangsu Province, China (CXLX11_0085).

\section{Author contribution}

Yang Qiao carried out the clinical study, data acquisition and manuscript preparation. Guixiong Gu participated in the design of the study and manuscript review. Jinlu Feng performed the statistical analysis. Jianping Yang carried out data acquisition. All the authors read and approved the final manuscript. There were no conflicts of interest.

\section{Conflict of interest}

The authors have declared that no conflict of interest exists.

\section{REFERENCES}

1) Bruses JL, Rutishauser U. 2001. Roles, regulation, and mechanism of polysialic acid function during neural development. Biochimie 83: 635-643.

2) Wang B, Brand-Miller J. 2003. The role and potential 
of sialic acid in human nutrition. Eur J Clin Nutr 57: 1351-1369.

3) Wang B, Yu B, Karim M, Hu H, Sun Y, McGreevy P, Petocz P, Held S, Brand-Miller J. 2007. Dietary sialic acid supplementation improves learning and memory in piglets. Am J Clin Nutr 85: 561-569.

4) Wang B. 2009. Sialic acid is an essential nutrient for brain development and cognition. Аnпи Rev Nutr 29: 177-222.

5) Nakano T, Sugawara M, Kawakami H. 2001. Sialic acid in human milk: composition and functions. Acta Paediatr Taiwanica (Taiwan er ke yi xue hui za zhi) 42: 11-17.

6) Pan XL, Izumi T. 2000. Variation of the ganglioside compositions of human milk, cow's milk and infant formulas. Early Hum Dev 57: 25-31.

7) Wang B, Brand-Miller J, McVeagh P, Petocz P. 2001. Concentration and distribution of sialic acid in human milk and infant formulas. Am J Clin Nutr 74: 510-515.

8) Fischer LM, da Costa KA, Galanko J, Sha W, Stephenson B, Vick J, Zeisel SH. 2010. Choline intake and genetic polymorphisms influence choline metabolite concentrations in human breast milk and plasma. Am J Clin Nutr 92: $336-346$.

9) Peng Y, Zhou T, Wang Q, Liu P, Zhang T, Zetterstrom R, Strandvik B. 2009. Fatty acid composition of diet, cord blood and breast milk in Chinese mothers with different dietary habits. Prostaglandins Leukot Essent Fatty Acids 81: 325-330.

10) Hai-jiao C. 2011. Determination of total sialic acid content in human milk by HPLC-FLD. Food Sci 32: 308311.

11) Chinese Nutrition Society. 2006. Chinese Dietary Reference Intakes. China Light Industry Publishing House, Beijing.

12) Thompson JM, Wall C, Becroft DM, Robinson E, Wild CJ, Mitchell EA. 2010. Maternal dietary patterns in pregnancy and the association with small-for-gestationalage infants. Br J Nutr 103: 1665-1673.

13) Carlson SE. 1985. N-acetylneuraminic acid concentrations in human milk oligosaccharides and glycoproteins during lactation. Am J Clin Nutr 41: 720-726.

14) Bode L. 2006. Recent advances on structure, metabolism, and function of human milk oligosaccharides. $J$ Nutr 136: 2127-2130.

15) Bode L. 2009. Human milk oligosaccharides: prebiotics and beyond. Nutr Rev 67 (Suppl 2): S183-S191.

16) Innis SM, Kuhnlein HV. 1988. Long-chain n-3 fatty acids in breast milk of Inuit women consuming traditional foods. Early Hum Dev 18: 185-189.

17) Vuori E, Kiuru K, Makinen SM, Vayrynen P, Kara R, Kuitunen P. 1982. Maternal diet and fatty acid pattern of breast milk. Acta Paediatr Scand 71: 959-963.

18) Wolf G, Johnson BC. 1960. Vitamin A and mucopolysaccharide biosynthesis. Vitam Horm 18: 439-455.

19) Wolf G, Varandani PT, Johnson BC. 1961. Vitamin A and mucopolysaccharide synthesizing enzymes. Biochim Biophys Acta 46: 59-67.

20) Chan VT, Wolf G. 1987. The role of vitamin A in the glycosylation reactions of glycoprotein synthesis in an 'in vitro' system. Biochem J 247: 53-62.

21) Kiorpes TC, Molica SJ, Wolf G. 1976. A plasma glycoprotein depressed in vitamin A deficiency in the rat: alpha 1-macroglobulin. J Nutr 106: 1659-1667.

22) Wolf G, Kiorpes TC, Masushige S, Schreiber JB, Smith MJ, Anderson RS. 1979. Recent evidence for the participation of vitamin A in glycoprotein synthesis. Fed Proc 38: $2540-2543$.

23) Schauer R, Kamerling J. 1997. Vol 29, Pt B: Chemistry, biochemistry and biology of sialic acids. In: New Comprehensive Biochemistry (Montreuil J, Vliegenthart J, Schachter H, eds), p 243-402.

24) Varki A. 1992. Diversity in the sialic acids. Glycobiology 2: $25-40$.

25) Olson JA. 1987. Recommended dietary intakes (RDI) of vitamin A in humans. Am J Clin Nutr 45: 704-716.

26) Tangvoranuntakul P, Gagneux P, Diaz S, Bardor M, Varki N, Varki A, Muchmore E. 2003. Human uptake and incorporation of an immunogenic nonhuman dietary sialic acid. Proc Natl Acad Sci USA 100: 12045-12050.

27) Varki A. 2009. Multiple changes in sialic acid biology during human evolution. Glycoconj J 26: 231-245.

28) Muzhingi T, Gadaga TH, Siwela AH, Grusak MA, Russell RM, Tang G. 2011. Yellow maize with high betacarotene is an effective source of vitamin A in healthy Zimbabwean men. Am J Clin Nutr 94: 510-519.

29) Tang G, Gu X, Hu S, Xu Q, Qin J, Dolnikowski GG, Fjeld CR, Gao X, Russell RM, Yin S. 1999. Green and yellow vegetables can maintain body stores of vitamin A in Chinese children. Am J Clin Nutr 70: 1069-1076. 